\title{
BMJ Open The moderating role of personal resources in the relationship between psychosocial job demands and health: a cross-sectional study
}

\author{
Hannes Mayerl, ${ }^{1}$ Erwin Stolz, ${ }^{1}$ Franziska Großschädl, ${ }^{2}$ Éva Rásky, ${ }^{1}$ Wolfgang Freidl ${ }^{1}$
}

To cite: Mayerl H, Stolz E, Großschädl $\mathrm{F}$, et al. The moderating role of personal resources in the relationship between psychosocial job demands and health: a crosssectional study. BMJ Open 2017;7:e015710. doi:10.1136/ bmjopen-2016-015710

- Prepublication history and additional material are available. To view these files please visit the journal online (http://dx.doi org/10.1136/bmjopen-2016015710).

Received 22 December 2016 Revised 8 June 2017

Accepted 10 July 2017

\section{CrossMark}

${ }^{1}$ Institute of Social Medicine and Epidemiology, Medical University of Graz, Graz, Austria

${ }^{2}$ Institute of Nursing Science, Medical University of Graz, Graz, Austria

Correspondence to

Hannes Mayerl;

hannes.mayerl@medunigraz.at

\section{ABSTRACT}

Objective The main objective of this research was to investigate the buffering effects of an individual's physical, mental and social resources in the relationship between psychosocial job demands and (1) health symptoms, (2) mental strain and (3) the body mass index (BMI), respectively.

Methods We performed moderated regression analysis to examine data from a large cross-sectional survey of an Austrian employee sample $(n=9434)$.

Results The results revealed a robust association between psychosocial job demands and health symptoms as well as mental strain, but only a weak relationship between psychosocial job demands and BMI. Although the personal resources showed a positive effect on health symptoms and mental strain, only weak evidence was found for the hypothesised interaction with psychosocial job demands. Solely the physical fitness of a person was found to mitigate the impact of psychosocial job demands on health symptoms.

Conclusions In conclusion, personal resources substantially accounted for the prediction of health. However, the interactions between psychosocial job demands and personal resources only slightly contributed to explaining the variation in health.

\section{INTRODUCTION}

In our modern society, the phenomenon of stress is ubiquitous. Especially, psychosocial stressors represent a major risk factor for ill health. ${ }^{1}$ Among other things, psychosocial stress was found to be related to musculoskeletal problems, ${ }^{2}$ psychosomatic complaints, ${ }^{3}$ sleep disturbances ${ }^{4}$ and mental health issues. ${ }^{5}$ More recent findings also suggested a relationship between chronic stress and weight gain, ${ }^{6-8}$ mediated through (neuro-)physiological processes, ${ }^{9-11}$ eating behaviour ${ }^{12}$ and physical activity. $^{13}$

Particularly in a working context, the relationship between stress and health has been extensively investigated and several models have been proposed in order to explain the origins of work-related stress
Strengths and limitations of this study

- The large and representative sample allowed us to make comprehensible inferences on the population of full-time employees in Austria

- We designed an extensive regression model, which was apt to explain considerable proportions of the variation in health.

- Given the cross-sectional nature of this study, no claims can be made about causality.

and its consequences. ${ }^{14}$ According to the job demands-control (JD-C) model, ${ }^{15}{ }^{16}$ stress reactions are supposed to be the consequence of a combination between high job demands and low autonomy at the workplace. A review of the JD-C model has shown good empirical support for health effects of job demands, but weak evidence for the hypothesised interaction between job demands and job control in predicting health. ${ }^{17}$

Another widely used model is the effortreward (ER) model. ${ }^{18}$ This model maintains that stress reactions are due to the feeling that despite the high efforts made at work the reward (eg, in terms of payment) remains insufficient. In a review, good empirical evidence was found for the negative impact of high efforts and low rewards combined, in terms of cardiovascular outcomes, psychosomatic symptoms, exhaustion and well-being. ${ }^{19}$ One limitation of the JD-C and the ER models is that they restrict themselves to specific types of demands or resources and thus these models lack flexibility. ${ }^{20}$

One popular model integrating previous work-related stress concepts is the job demands-resources (JD-R) model. ${ }^{21}$ Unlike the JD-C and the ER models, the JD-R model considers any combination of different types of job demands and job resources in predicting health and well-being. ${ }^{20}$ Job demands relate to all job factors that entail 
psychological or physical costs due to accelerated efforts. Job resources, by contrast, are defined as all physical, psychological, social and organisational factors that are beneficial to goal attainment, reduce costs due to job demands or facilitate growth and advancement. ${ }^{2122}$

The JD-R model proposes two main effects ${ }^{22}$ : the first effect is about health problems when individuals are exposed to high job demands beyond their resources. The second effect concerns the motivational aspects of job resources. Where resources are high, higher work engagement, lower cynicism and better job performance are expected. ${ }^{23}$ In addition to these two main effects, the JD-R model predicts an interaction between job demands and job resources in explaining mental and somatic health. On the one hand, job resources are thought to have the potential to buffer the negative impact of job demands on health while, on the other hand, individuals working in low-resource environments are thought to be especially vulnerable to job demands. These assumptions were confirmed in a study demonstrating that the combination of low job resources and high job demands was associated with higher levels of burnout symptoms. ${ }^{24}$

A potential weakness of the JD-R model is that it focuses exclusively on job resources, while disregarding personal characteristics of individuals. ${ }^{20}$ As most psychological stress models assume that the stress response depends on the interaction between the individual and its environment, ${ }^{14}$ extensions of the JD-R model have been proposed in order to include personal resources as well. While job resources refer to favourable factors in a person's working environment, personal resources relate to those aspects of the self that are associated with resilience. ${ }^{25}$ An individual with a high amount of personal resources may perceive a specific situation as less demanding than a person low in personal resources, believing that the resources available to him/her would suffice to efficiently handle the situation and to cope with the consequences. ${ }^{26}{ }^{27}$ Taking both job resources and personal resources into account, therefore, enables a better understanding of the stress phenomenon. Although the definition of personal resources implies the moderating effect of personal resources in the relationship between job demands and health, the empirical evidence for this effect remains rather weak and ambiguous. ${ }^{28}$

Previous studies with personal resources integrated in the JD-R model concentrated on mental aspects, such as self-efficacy, self-esteem or optimism. ${ }^{28-30}$ This may be considered to be a limitation, as the biological and social characteristics of individuals are neglected. For instance, it has been shown that physically fitter persons-although displaying a slightly higher reactivity to stress—showed quicker recovery from a stressful situation than people who were less fit. ${ }^{31}$ Additionally, in a recent experiment, physically fitter persons had a less strong inflammatory cytokine response to mental demands than persons with poor fitness. ${ }^{32}$ These study results indicate that physical fitness may help to buffer the negative impact of excessive job demands on health. Furthermore, a meta-analysis has found social support to play a crucial role in the relationship between job demands and stress reactions. ${ }^{33}$ The perception of being part of a social network or having friends who help in difficult situations is seen to be an important resource, with a capacity of buffering the influence of high demands on health outcomes. Thus, we defined personal resources in line with a bio-psycho-social way of thinking, ${ }^{34}$ as those biological, mental and social aspects that may positively enhance an individual's resilience against several kinds of demands. ${ }^{35}$

\section{The current study}

In our study, we operationalised job demands as the burden emanating from psychosocial demands at the workplace. These include those psychological and social aspects of the job that are subjectively experienced as demanding and require sustained efforts on the part of employees. ${ }^{21}$ As regards the personal resources, we used three indicators to account for biological, mental and social aspects. More specifically speaking, we used the subjective evaluation of a person's physical fitness as an indicator for the biological aspect. The mental aspect referred to the concept of generalised self-efficacy, defined as a stable and global belief of being able to mobilise one's own skills in order to solve a specific problem or to attain a specific goal. ${ }^{3637}$ As for the social component, we concentrated on social support outside of work.

The outcome variables in our study comprised aspects of both mental and somatic health. More concretely, the somatic health outcomes referred to self-reported health symptoms on the one hand and the body mass index (BMI) on the other hand. We used BMI as health outcome since the prevalence of obesity is increasing worldwide ${ }^{38}$ and elucidating the determinants for increased weight is thus of major interest for public health. As regards mental strain reactions, we focused on irritation, alienation and exhaustion. Irritation is seen as a state of mental impairment comprised of emotional irritation. ${ }^{39}$ Alienation refers to psychological separation or estrangement from the self. ${ }^{40}$ Exhaustion is seen as the central quality of burnout, representing feelings of being depleted of one's resources. ${ }^{4}$

Against this backdrop, we defined three main hypotheses:

1. Based on extensive evidence for a detrimental impact of high demands on health, we expected a positive linear relationship to exist between psychosocial job demands and the three health outcomes.

2. As personal resources had been found to be a beneficial factor for health, we predicted that individuals high in personal resources would report less health symptoms, less mental strain and lower BMIs than those low in personal resources.

3. We hypothesised that the impact of psychosocial job demands on health would depend on the amount of personal resources available. That is, the consequences of psychosocial job demands on health outcomes would be less harmful for those availing of 
a great pool of personal resources. Thus, we expected each of the physical, mental and social resources to moderate the relationships between psychosocial job demands and health outcomes.

\section{METHODS \\ Data collection and participants}

Data were collected among the Austrian working population by The Institute for Empirical Social Studies (IFES) on behalf of the Upper Austrian Chamber of Labour from 2012 to 2014. A sample consisting of 14946 persons was drawn using proportionally stratified random sampling. Self-reported data concerning demographics, working conditions and health-related characteristics were collected using the face-to-face structured interviewing method. Prior to the interview, participants were informed about the study objectives and on the confidentiality and anonymity of the collected data. Permission to interview was obtained in the form of verbal informed consent. Since the health-related items were only presented to employed (full-time) persons, the sample size reduced to $\mathrm{n}=9434$ participants. Totally $50.6 \%$ of the participants were male and the mean age across the sample was 39.7 years $(\mathrm{SD}=11.3$; range: $15-85$ years). A rate of $9.2 \%$ had completed compulsory school, $64.8 \%$ were skilled workers with an apprenticeship certificate or had a graduation from a vocational school, 13.3\% had a high school diploma and $12.8 \%$ held a university degree.

\section{Measures}

Items used in this research were partly derived from validated instruments, but were also selected as proxy measures representing the underlying constructs of interest. For the texts of all items used in this research as well as descriptive statistics and proportions of missing values for each measure, please refer to the information in the online supplementary materials.

\section{Dependent variables}

\section{Health symptoms}

Participants were asked to indicate how often in the last weeks they had suffered from: (1) digestive problems, (2) headache/migraine, (3) sleep disturbances, (4) fatigue, (5) nervousness, (6) lack of concentration, (7) back pain, (8) leg pain, (9) hypertension, (10) tachycardia, (11) skin problems, (12) respiratory problems or (13) chronic coughing. For each item, response categories ranged from ' $1=$ never' to ' $5=$ very often'.

\section{Mental strain}

(1) To assess irritation, we included three items (eg, "I anger quickly") from the German Irritation Scale ${ }^{43}$ developed for assessment of psychological strain in the context of work. (2) Alienation was operationalised with three items (eg, "I often do not understand what is actually happening") based on a subscale assessing the subjective feeling of being estranged from the self. ${ }^{44}$ (3) The burnout dimension emotional exhaustion ${ }^{45}$ was measured with three items in total (eg, "I feel exhausted due to work"). For each item measuring mental strain, response categories ranged from ' $1=\mathrm{I}$ do not agree' to ' $5=\mathrm{I}$ strongly agree'.

\section{Body mass index}

The BMI was calculated for each participant as the body weight (in kilograms), divided by the square of body height (in metres). The figures for body height and weight are based on self-reported data.

\section{Independent variables}

\section{Psychosocial job demands}

To assess psychosocial job demands, we used six items measuring the burden due to both psychological and social aspects at the workplace. Participants had to rate, on a five-point scale (' $1=$ not stressed' to ' $5=$ strongly stressed'), how strongly they felt burdened by (1) isolation at the workplace, (2) time pressure, (3) emotionally burdening and annoying work, (4) high responsibility for goods and people, (5) changes in work routines and (6) irregular working hours.

\section{Personal resources}

(1) Physical: We used two items defining physical constitution (eg, "How would you assess your physical fitness?") as an indicator for physical resources, measured on a five-point rating scale (from ' $1=$ very poor' to ' $5=$ very good'). (2) Mental: The mental component referred to the construct of self-efficacy, which was measured using three items (response categories ranging from ' $1=\mathrm{I}$ do not agree' to ' $5=I$ strongly agree') from a German version of the 'Generalized Self-efficacy Scale' (eg, "I can always manage to solve difficult problems if I try hard enough"). ${ }^{46}$ (3) Social: The social component was operationalised by three items (five-point rating scale ranging from ' $1=\mathrm{I}$ do not agree' to ' $5=\mathrm{I}$ strongly agree') assessing social support (eg, "I have persons beyond my immediate family circle, on whom I can count in case of emergency").

\section{Job resources}

(1) Job control was assessed using three items (eg, "How satisfied are you with the possibilities to decide on work processes.") measuring the amount of autonomy and decision latitude at work. (2) Job rewards were operationalised by three items assessing satisfaction with (1) income, (2) occupational training opportunities and (3) career and development opportunities. For all items, response categories ranged from ' $1=$ not at all satisfied' to ' $5=$ very satisfied'. We included job control and job rewards since these factors relate to the currently leading job stress models used in health psychology ${ }^{14} 20$ (along with the JD-R model), namely, the JD-C model ${ }^{15}$ and the ER model. ${ }^{18}$

\section{Health behaviour}

To measure health-related risk behaviour, we included dichotomous answers for items assessing whether 
participants performed regular exercise in their leisure time $(0=y e s / 1=$ no $)$, ate healthy food $(0=y e s / 1=$ no $)$ or smoked $(0=$ not at all $/ 1=$ occasionally or regularly). These variables were treated as dummy variables. Additionally, participants were asked to indicate, on a six-point scale (from ' $1=$ not at all' to ' $6=$ nearly every day'), how often they consumed alcohol.

We calculated estimates for health symptoms, job demands and each subscale of the personal and job resources by averaging the respective raw scores. As regards to mental strain, we averaged the mean scores for irritation, alienation and exhaustion to obtain an estimate for mental strain. All of these mean scores were subsequently used in our regression models. In order to examine the psychometric properties of these scales, we conducted confirmatory factor analysis (CFA) and estimated reliability.

\section{Psychometric and statistical analysis}

Psychometric analysis

We performed CFA to examine the dimensionality of the scales for health symptoms, mental strain, job demands, personal resources and job resources. We relied on polychoric correlations and diagonally weighted least squares estimation with robust test statistics (WLSMV estimation). ${ }^{48} 49$ To evaluate model fit, we focused on the Comparative Fit Index (CFI), the Tucker-Lewis Index (TLI) and the root mean square error of approximation (RMSEA). Values $\geq 0.95$ of the CFI and the TLI, and values $\leq 0.06$ of the RMSEA were defined as sufficient. ${ }^{50}$ Since CFA models with a total of two or three indicators were saturated, we only state the range of the factor loadings.

\section{Regression analysis}

To test our hypotheses, we used multiple linear regression analysis and moderated regression analysis. As we were interested in the relative importance of the three personal resources and their moderating effects, we applied a hierarchical approach: In model I, we regressed each of the three dependent variables on all independent variables except for the personal resources. In model II, the personal resources were added to the regression models as predictors, and in model III, we additionally considered the interactions between the three personal resources and job demands by including the product terms of the corresponding scores.

To handle missing data (1.28\% in total), we applied multiple imputation by chained equations. Each regression analysis was repeated for the $\mathrm{m}=20 \mathrm{imputed}$ data sets and the results were pooled according to Rubin's rules. ${ }^{51}$ All psychometric and statistical analyses were carried out with R V.3.1.2. ${ }^{52}$ CFA was done using the R-package lavaan V.0.5-1 $17^{53}$ while multiple imputation was carried out using the R-package mice V.2.22. ${ }^{54}$ Due to the large sample size, we set the significance threshold for hypothesis testing to $\alpha=1 \%$.

\section{RESULTS}

\section{Psychometric analysis}

Health symptoms

The one-factor model for health symptoms fitted the data sufficiently well $\left(\chi^{2}(65)=2058.5, p<0.001 ; \mathrm{CFI}=0.959\right.$; TLI $=0.951$; RMSEA $=0.057)$ and internal consistency was good (Cronbach's $\alpha=0.93$ ).

\section{Mental strain}

The model for mental strain consisted of three first-order factors-irritation, alienation and exhaustion-that form the second-order factor mental strain. This model adequately fitted the data $\left(\chi^{2}(24)=568.7, \quad \mathrm{p}<0.001\right.$; $\mathrm{CFI}=0.998 ; \quad \mathrm{TLI}=0.997 ; \quad \mathrm{RMSEA}=0.049)$ and internal consistency of the second-order factor was acceptable $(\alpha=0.76)$.

\section{Psychosocial job demands}

For psychosocial job demands, we tested a one-factor model. The indices confirmed model fit $\left(\chi^{2}(9)=257.7\right.$, $\mathrm{p}<0.001 ; \quad \mathrm{CFI}=0.990 ; \quad \mathrm{TLI}=0.984 ; \quad$ RMSEA $=0.054) \quad$ and internal consistency was sufficient $(\alpha=0.84)$.

\section{Personal resources}

(1) Physical: The factor loadings of the items measuring the physical component were $\lambda=0.75$ and $\lambda=0.89$. (2) Mental: The correlations between the latent factor and the items measuring self-efficacy were between $\lambda=0.81$ and $\lambda=0.86$. (3) Social: The factor loadings of the items assessing social support ranged from $\lambda=0.88$ to $\lambda=0.91$. Internal consistency for the physical $(\alpha=0.88)$, the mental $(\alpha=0.87)$ and the social $(\alpha=0.93)$ component was good.

\section{Job resources}

(1) Job control: The items measuring job control loaded on the latent factor in a range between $\lambda=0.56$ and $\lambda=0.89$. (2) Job rewards: The factor loadings of the items assessing job rewards ranged from $\lambda=0.54$ to $\lambda=0.91$. Internal consistency for job control $(\alpha=0.79)$ and job rewards $(\alpha=0.81)$ was sufficient.

\section{Regression analysis}

An overview of the coefficients of determination for models I-III can be found in table 1 . We found that adding the three personal resources as predictors in model II has significantly improved the prediction for health symptoms, mental strain and BMI. By additionally including the product terms between psychosocial job demands and each of the three personal resources as predictors in the third step, the predictions for health symptoms and mental strain were significantly enhanced when compared with the models in the second step. As for BMI, the inclusion of the product terms in the third step did not significantly increase the coefficient of determination. In the next paragraphs, we report the regression coefficients for model III, including all predictors and interactions. 


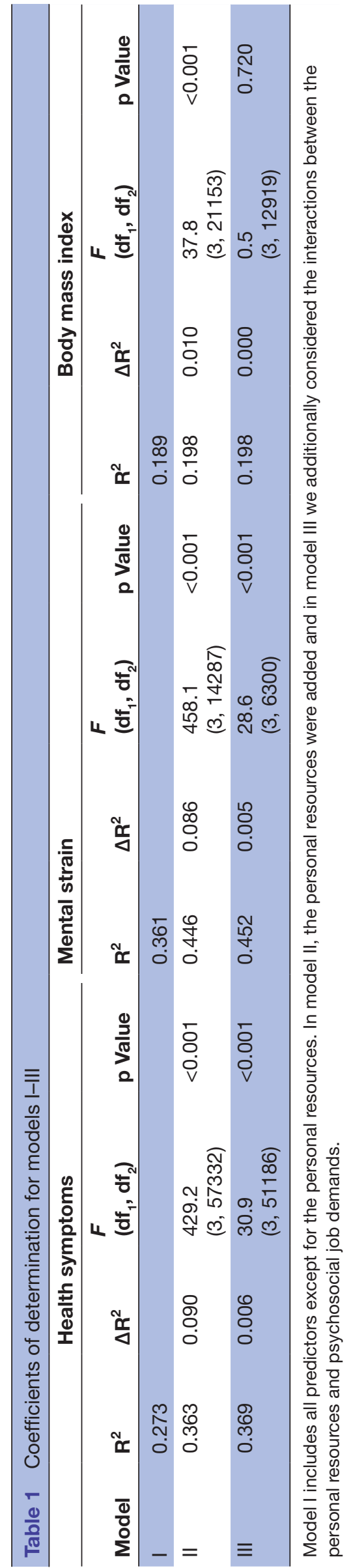

Health symptoms

Listed in table 2 are the results of the multiple regression analysis for health symptoms. There was a significant effect of psychosocial job demands on health symptoms, that is, higher amounts of job demands were accompanied with higher levels of health symptoms. Among the personal resources, the physical component had the relatively highest explanatory value, while there was an insignificant effect for the mental component and a significant but relatively weak effect for the social component.

However, physical resources also interacted with job demands. To clarify this interaction, figure 1 shows the simple slopes of psychosocial job demands for low (10th quantile), middle (50th quantile) and high (90th quantile) values for personal resources. As seen in the first row on the left, persons high in physical resources are expected to have less health symptoms than persons low in physical resources. Moreover, good physical fitness seemed to buffer the impact of job demands on health symptoms. The predicted values for health symptoms increased less strongly as a function of psychosocial job demands in those high in physical resources than in those low in physical resources. Looking at the central and the right figure in the first row, neither a difference in health symptoms between the three lines nor a clear interaction effect between the personal resources and psychosocial job demands is evident.

In table 2, for the job resources we found a significant effect only for job rewards. That is, persons who reported more rewards reported less health symptoms. Among the health-related behaviours, only the variable exercise was related to health symptoms. Persons who actively practised sports stated more health symptoms than those not actively practising sports. Furthermore, the health status worsened with increased age, and, overall, women (vs men) and employees with a high school diploma (vs compulsory education) reported more health symptoms, respectively. Marital status showed no impact.

\section{Mental strain}

As seen in table 2, psychosocial job demands had a relatively strong relation to mental strain. On the other hand, there were negative effects for the physical, mental and social components of personal resources, respectively. However, we also found an interaction effect between job demands and personal resources. The second row of figure 1 reveals higher levels of mental strain in those low in personal resources than in those high in personal resources, whereby the difference was greater for the physical and mental components and smaller for the social component. However, the interaction effects appear to be relatively weak and the practical implications are questionable.

As for the job resources, higher job control was related to less mental strain. Among the health-related behaviours, the variables diet and smoking were related to mental strain. Unhealthy diet and smoking seemed to 


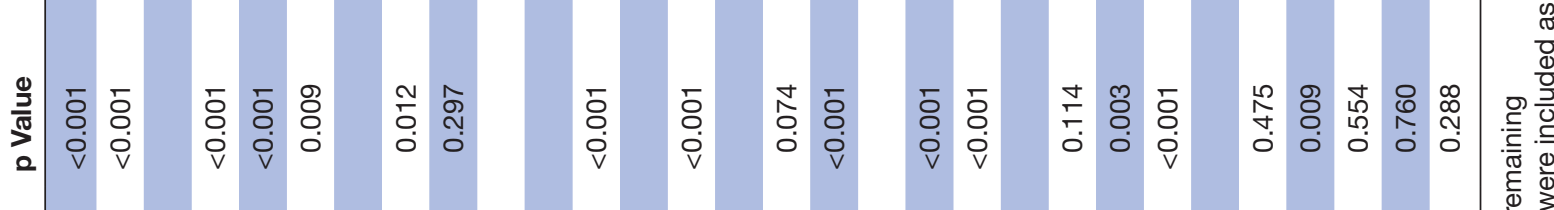

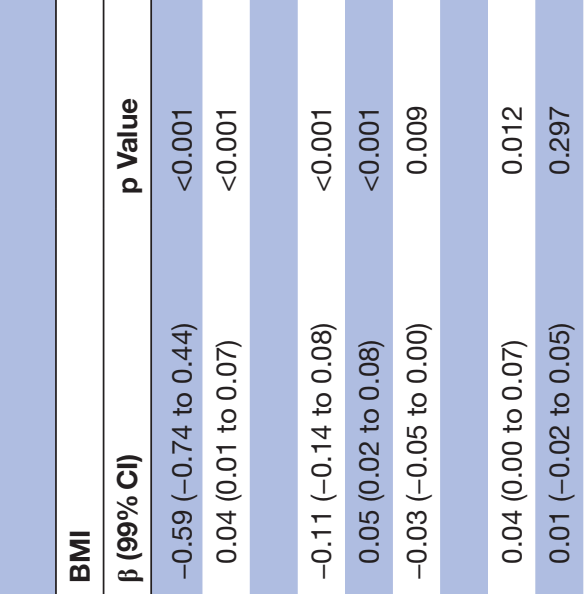

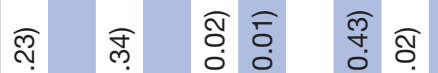

ชิ สิธ 도

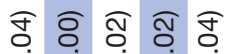

०० 0

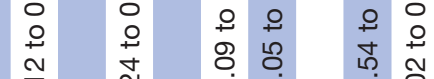

운 웅

- 0 0 00

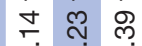

웅ㅇㅇㅇㅇㅇㅇ

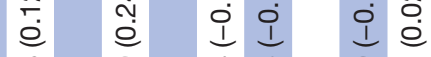

i 1

\%

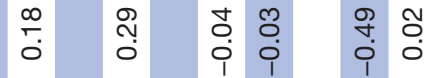

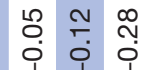

1 I I 1 i 19

๙ิ 80505

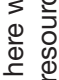

웓

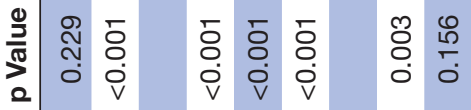

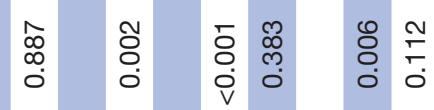

$\begin{array}{lll}\bar{\delta} & \bar{\delta} & 0 \\ 0 & 0 \\ \dot{0} & 0 & 0\end{array}$

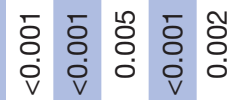

ญั ญ

焉

这

음

든

so

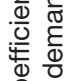

은 은

交

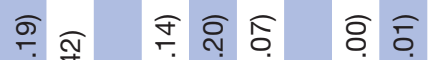

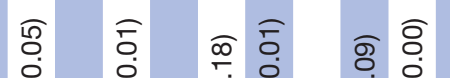

ชิ $\overline{0}$

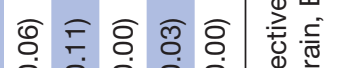

$\begin{array}{lll}0 & 0 \\ 0 & 0 & 0 \\ 0 & 0\end{array}$

0 0 0 0 0

웅ㅇ 오

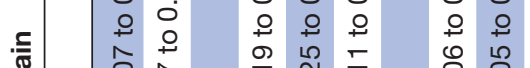

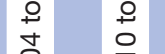

잉

웅

용

뉸

$\begin{array}{lll}0 & 0 \\ 0 & 0\end{array}$

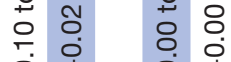

ํ.

i 1 i 1

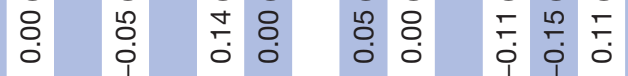

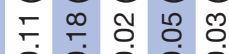

की $\frac{0}{20}$

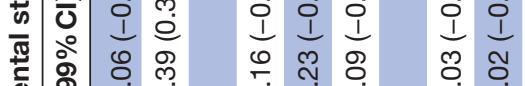

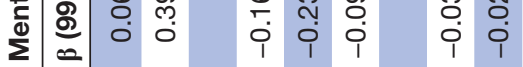

i i 1 i 1

$\sum_{m}$

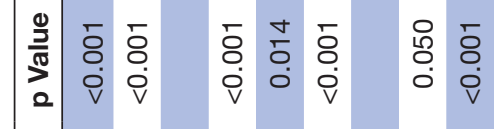

들

푱

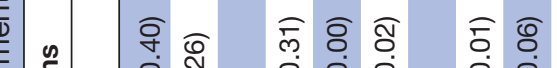

है

은

के

क

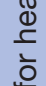

के

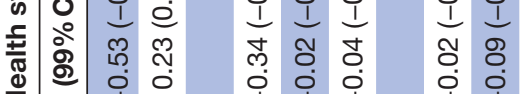

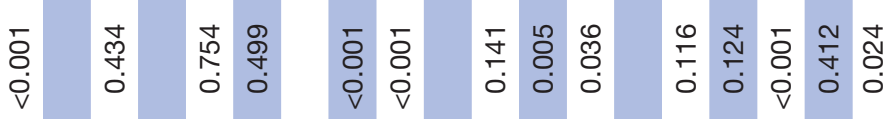

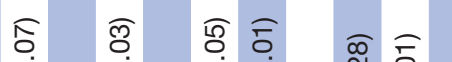

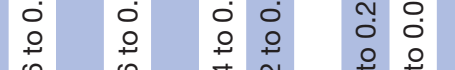

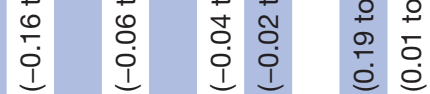

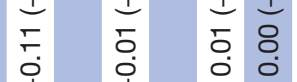

อ 巳

Nָ
ลิ

$\begin{array}{llll}0 & 0 \\ 0 & 0 & 0 & 0 \\ 0 & 0 & 0 \\ 0 & 0 & 0 & 0 \\ 0 & 0 & 0\end{array}$

ำ 웅

$\begin{array}{lll}1 & 0 & 1 \\ 0 & 0 & 0 \\ 0 & 0 & 0 \\ 0 & 0 & 0\end{array}$

\begin{tabular}{lll}
\hline & 0 & 0 \\
0 & 0 & 0 \\
0 & 0 & 0 \\
0
\end{tabular}
สิธ

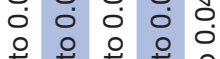
은 는 은 $\begin{array}{lllll}1 & 0 & 0 & 0 & 0 \\ 1 & 1 & 1 & 1 & 0 \\ 1 & 0 & 0\end{array}$ गु

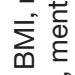

으 ㅇํㅇ

के है

퓰 동

巡

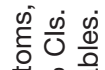

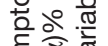

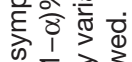

들 흐웜

유을 응

훈

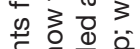

넌 की

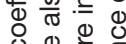

ᄂ 3

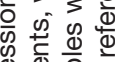

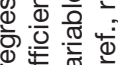

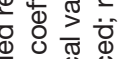

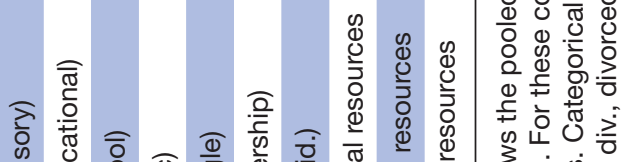

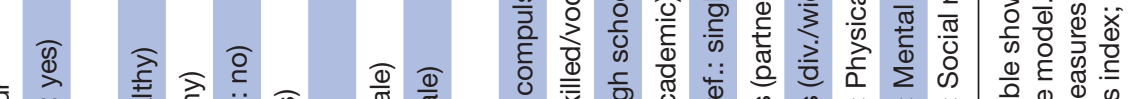

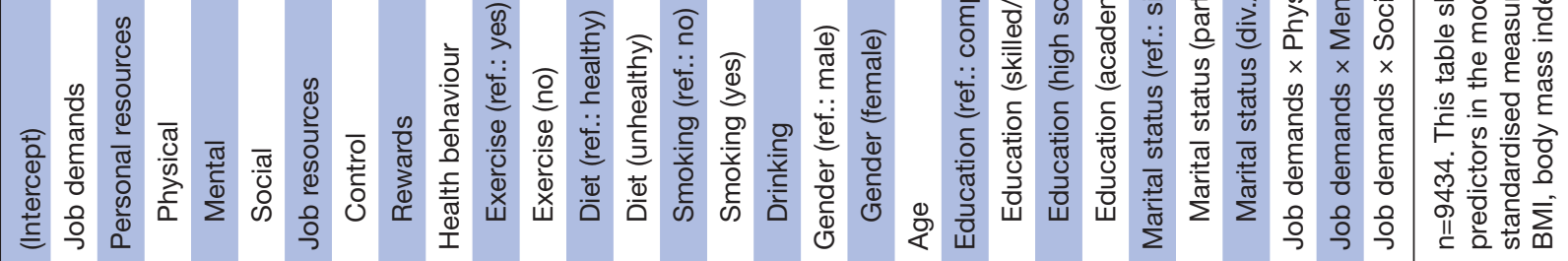

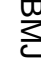

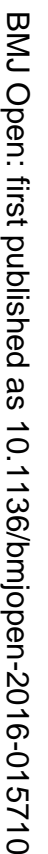

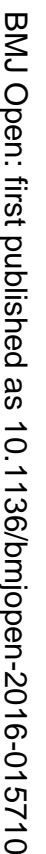

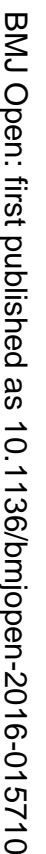

ㅇ

$\infty$

胥

क

$\stackrel{\text { N }}{\stackrel{0}{*}}$

ํํำ

흠

$\frac{1}{1}$

훙

要

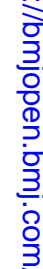

$\stackrel{9}{3}$

N

N

ए

$\stackrel{0}{\frac{0}{D}}$

$\underset{\mathbb{D}}{\stackrel{7}{7}}$

Tợ

융

$\stackrel{\circ}{10}$

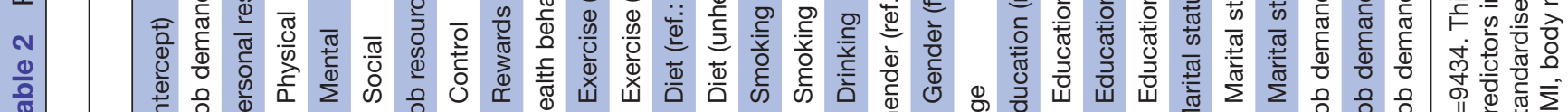



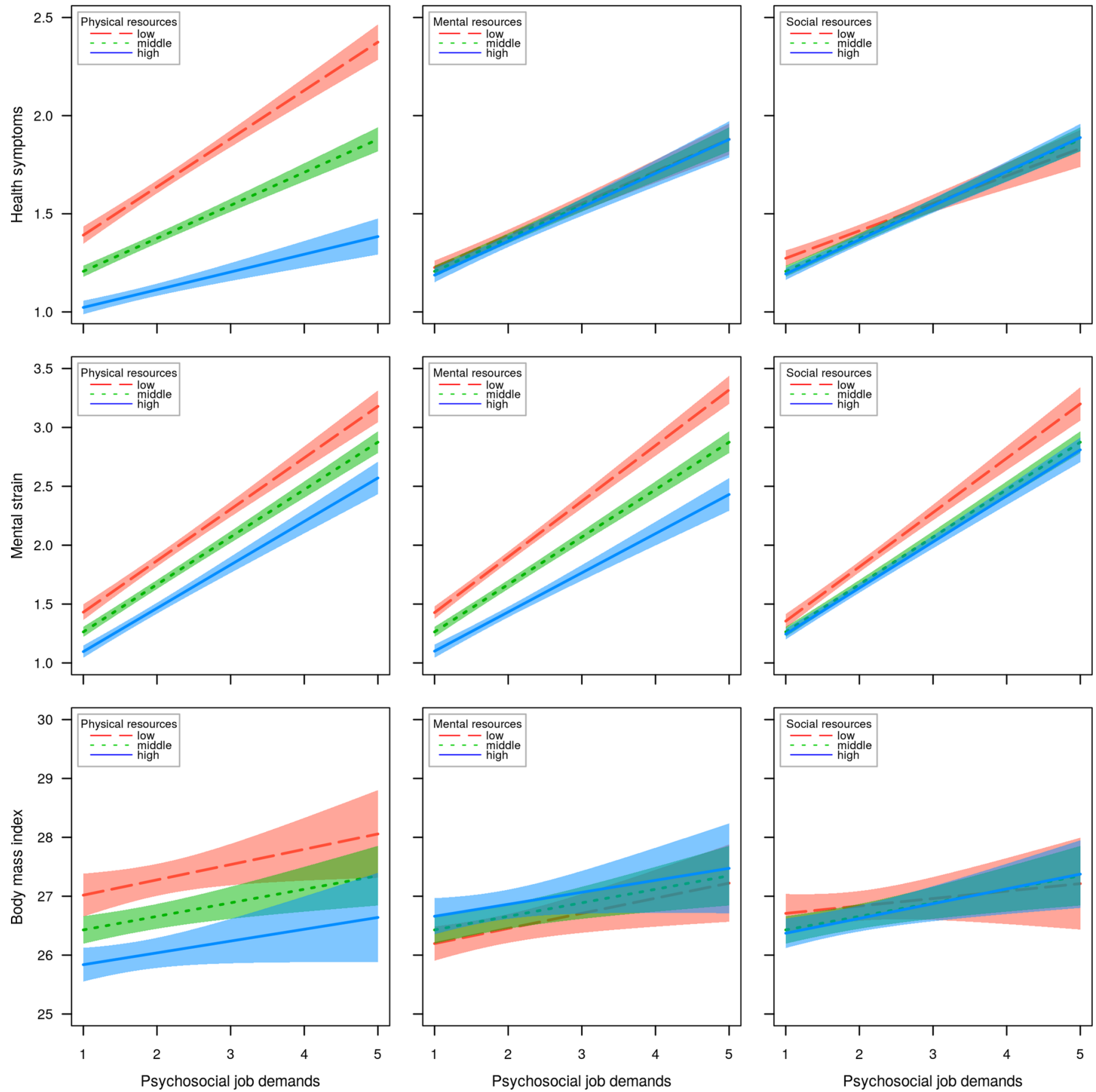

Figure 1 Prediction of the health outcomes as a function of psychosocial job demands and personal resources. The figures show the predicted lines (model III) with 99\% confidence bands for health symptoms, mental strain and body mass index. The coloured lines refer to the classification of the personal resources in low (10th quantile), middle (50th quantile) and high (90th quantile) values. The figures are based on the first imputed complete data set.

be accompanied with higher levels of mental strain. In general, women indicated to experience more mental strain than men. Age in turn had no impact. Considering the educational level, university graduates (vs employees with compulsory education) indicated higher levels of mental strain, and skilled workers/graduates from a vocational school and workers with a high school diploma reported less levels of mental strain. Regarding marital status, persons in a partnership as well as divorced/ widowed persons reported lower levels of mental strain than singles.

Body mass index

Although there was a significant positive relationship between psychosocial job demands and BMI, the effect was less strong than for health symptoms and mental strain. The findings concerning the personal resources were ambiguous. Physical and social resources were negatively associated with BMI and mental resources were 
positively related to BMI. Additionally, none of the interactions between psychosocial job demands and either of the three personal resources were significant (also see figure 1, third row).

Regarding job resources, we found that persons who reported higher job control had a higher BMI. Hardly surprising was health-related behaviour related to BMI. Unhealthy diet and lack of exercise were accompanied by a higher BMI. Smoking was not related to BMI, and alcohol consumption was negatively related to BMI. Furthermore, university graduates and workers with a high school diploma had a lower BMI than workers with compulsory education. In addition, divorced/widowed persons had a lower BMI than singles.

\section{DISCUSSION}

The main objective of this study was to uncover physical, mental and social resources that can be beneficial in maintaining individual health despite a high burden due to psychosocial demands experienced at the workplace. In line with the first hypothesis, we found a robust positive association between psychosocial job demands and health symptoms as well as mental strain. These study results support previous prospective studies demonstrating that people working in psychosocially demanding environments have a greater risk for somatic ${ }^{55} 56$ and mental health issues. ${ }^{5758}$ We also expected to find a positive relationship between psychosocial job demands and BMI. ${ }^{79}$ However, although this effect was significant, the relative explanatory value was low in comparison with other predictors in the model. The reason for this weak effect may be due to a bidirectional impact of job demands on body weight. This means that the burden due to high job demands may cause some people to reduce their food intake and lose weight and other people to eat more and gain weight. Indeed, in a longitudinal study, work-related stress showed an increase of the BMI in overweight persons but a reduction in lean persons. ${ }^{60}$

The findings for the second and third main hypotheses are discussed in more detail below. For health symptoms, a relatively clear relationship was found with physical resources. On the one hand, we found that persons high in physical fitness reported less health symptoms than those low in physical fitness, and on the other hand, that physical fitness seems to be a beneficial factor buffering the negative influences of psychosocial job demands on health. These results support previous conclusions concerning physical fitness as a crucial factor in the relationship between stress and somatic health and wellbeing. ${ }^{6162}$ It may be argued that fitter persons are more able to cope with psychosocial demands while exhibiting a less strong physiological activation which otherwise, in the long term, may result in bodily damages. ${ }^{6364}$ Our findings must, however, be interpreted with some caution. This cross-sectional study does not allow us to tell cause from effect, so longitudinal studies will be needed to examine the effect the interaction between physical resources and job demands has on health over time. We also expected the mental and social resources of an individual to be further factors for buffering the negative impact of psychosocial job demands on health symptoms. However, we did not find any effect that was strong enough to have practical implications.

For mental strain, our findings regarding the predicted positive effects of personal resources were relatively straightforward. In other words, physical fitness, the confidence in one's own abilities and a helpful circle of friends appeared to promote mental health. ${ }^{355}$ However, although the hypothesised interaction effects were significant, they remained small. Regarding the relationship between BMI and personal resources, there was only one result confirming our hypotheses in that we found a negative association between BMI and physical resources. Little surprisingly, individuals feeling physically fit had a lower BMI than those with poor physical fitness. On the other hand, higher levels of mental resources were accompanied by a slightly higher BMI. This result somewhat contradicted the results of previous studies. For example, in a recent study, it has been found that individuals high in self-efficacy had a lower BMI than those low in self-efficacy. ${ }^{66}$ Moreover, in terms of the hypothesised moderating effect of personal resources, we did not find a significant result.

Overall, we found that including the personal resources substantially improved the prediction for health symptoms and mental strain. These findings clearly support recent approaches of considering personal resources in work-related stress models. ${ }^{28}{ }^{29}$ On the other hand, by adding the interactions between psychosocial job demands and the personal resources, the change of explained variance was relatively weak. Hence, it remains questionable whether personal resources should be treated as moderators in the relationship between job demands and health. Apart from the buffering effect found for physical resources regarding the impact of psychosocial job demands on health symptoms, the interaction effects only slightly contributed to the prediction.

\section{Strengths and limitations}

One shortcoming of our study concerns its cross-sectional nature. The effects are only correlational and no causal inferences can be made. Longitudinal studies will thus be needed in order to investigate the causal relationships between job demands, health and the different components of personal resources. A further limitation might reside in the self-reported character of the analysed data and in the fact that the measures yielded only approximate indices of the respective underlying constructs. More objective and standardised measures (eg, physical fitness tests as an indicator for physical resources) might have led to more reliable findings. Furthermore, it might be considered a limitation that we used BMI as an indicator for health. Although increased weight is among the most significant contributors to morbidity and mortality, ${ }^{38}$ the BMI has been often criticised because it only considers 
weight and height and disregards other factors, such as muscle and bone mass or fat reserves. This might be one of the reasons why most studies in this context found only weak associations between stress and BMI.

One strength of our research is that we designed an extensive model, which was apt to explain considerable proportions of the variation in mental strain $(45 \%)$ and health symptoms (37\%). A further strength of our study was the representative large-size sample, which allowed us to make comprehensible inferences to the working population in Austria. However, since we restricted our sample to employees working full time, our findings only related to this group of individuals and no inferences can be made on other groups, such as part-time workers or the self-employed.

\section{Conclusion and practical implications}

Three conclusions can be drawn:

1. High psychosocial job demands were related to higher levels of health symptoms and of mental strain.

2. Personal resources in a bio-psycho-social sense may be beneficial factors for somatic and mental health.

3. Concerning the moderating role of personal resources, we found that physical fitness seemed to attenuate the negative impact of psychosocial job demands on somatic health.

Our findings suggest that organisational goals should especially address the reduction of overwhelming psychosocial job demands in order to decrease work-related health problems. A further objective for health promotion concerns the empowerment of the employee's personal resources. In highly demanding working environments particularly high physical fitness of a person may have the potential to cushion the detrimental effects that psychosocial job demands have on somatic health. Thus, the promotion of physical fitness is a higher purpose when it comes to preventing health problems in highly demanding jobs.

Acknowledgements We are grateful to the Upper Austrian Chamber of Labour for regularly collecting data in order to monitor work climate and mental and somatic health of employees. We would also like to thank them for the good cooperation and for providing us with the data.

Contributors HM, WF and ES conceived and designed the study. HM, WF and ES analysed the data. HM wrote the paper. WF, ES, FG and ER critically reviewed drafts of the paper. HM, WF, ES, FG and ER interpreted the study findings. All authors approved the final version of the manuscript.

Competing interests None declared.

Ethics approval The Ethics Committee of the Medical University of Graz approved the conductance of this study (EK-number: 27-251 ex 14/15).

Provenance and peer review Not commissioned; externally peer reviewed.

Data sharing statement № additional data are available.

Open Access This is an Open Access article distributed in accordance with the Creative Commons Attribution Non Commercial (CC BY-NC 4.0) license, which permits others to distribute, remix, adapt, build upon this work non-commercially, and license their derivative works on different terms, provided the original work is properly cited and the use is non-commercial. See: http://creativecommons.org/ licenses/by-nc/4.0/ (c) Article author(s) (or their employer(s) unless otherwise stated in the text of the article) 2017. All rights reserved. No commercial use is permitted unless otherwise expressly granted.

\section{REFERENCES}

1. Nixon AE, Mazzola JJ, Bauer J, et al. Can work make you sick? A meta-analysis of the relationships between job stressors and physical symptoms. Work Stress 2011;25:1-22.

2. Bongers PM, de Winter CR, Kompier MA, et al. Psychosocial factors at work and musculoskeletal disease. Scand J Work Environ Health 1993;19:297-312.

3. Frese M. Stress at work and psychosomatic complaints: a causal interpretation. J Appl Psychol 1985;70:314-28.

4. Akerstedt T. Psychosocial stress and impaired sleep. Scand J Work Environ Health 2006;32:493-501.

5. Stansfeld S, Candy B. Psychosocial work environment and mental health--a meta-analytic review. Scand J Work Environ Health 2006;32:443-62.

6. Block JP, He Y, Zaslavsky AM, et al. Psychosocial stress and change in weight among US adults. Am J Epidemiol 2009;170:181-92.

7. Harding JL, Backholer K, Williams ED, et al. Psychosocial stress is positively associated with body mass index gain over 5 years: evidence from the Longitudinal AusDiab study. Obesity 2014;22:277-86.

8. Kouvonen A, Kivimäki M, Cox SJ, et al. Relationship between work stress and body mass index among 45,810 female and male employees. Psychosom Med 2005;67:577-83.

9. Hamer M, Stamatakis E. Inflammation as an intermediate pathway in the association between psychosocial stress and obesity. Physiol Behav 2008;94:536-9.

10. Jauch-Chara K, Oltmanns KM. Obesity--a neuropsychological disease? systematic review and neuropsychological model. Prog Neurobiol 2014;114:84-101.

11. Kyrou I, Tsigos C. Chronic stress, visceral obesity and gonadal dysfunction. Hormones 2008;7:287-93.

12. Torres SJ, Nowson CA. Relationship between stress, eating behavior, and obesity. Nutrition 2007;23:887-94.

13. Holmes ME, Ekkekakis P, Eisenmann JC. The physical activity, stress and metabolic syndrome triangle: a guide to unfamiliar territory for the obesity researcher. Obes Rev 2010;11:492-507.

14. Mark GM, Smith AP. Stress models: a review and suggested new direction. In: Houdmont J, Leka S, eds. Occupational Health Psychology. Nottingham: Nottingham University Press, 2008:111-44.

15. Karasek RA, demands J. Job Demands, Job Decision Latitude, and Mental Strain: implications for Job Redesign. Adm Sci Q 1979;24:285-308.

16. Karasek R. Lower health risk with increased job control among white collar workers. J Organ Behav 1990;11:171-85.

17. de Lange AH, Taris TW, Kompier MA, et al. "The very best of the millennium": longitudinal research and the demand-control-(support) model. J Occup Health Psychol 2003;8:282-305.

18. Siegrist J. Adverse health effects of high-effort/low-reward conditions. J Occup Health Psychol 1996;1:27-41.

19. van Vegchel $\mathrm{N}$, de Jonge J, Bosma $\mathrm{H}$, et al. Reviewing the effortreward imbalance model: drawing up the balance of 45 empirical studies. Soc Sci Med 2005;60:1117-31.

20. Schaufeli WB, Taris TW. A Critical Review of the Job DemandsResources Model: Implications for Improving Work and Health. In: Bauer GF, Hämmig O, eds. Bridging Occupational, organizational and Public Health: a Transdisciplinary Approach. Dordrecht: Springer Netherlands, 2014:43-68.

21. Demerouti E, Bakker AB, Nachreiner F, et al. The job demandsresources model of burnout. J Appl Psychol 2001;86:499-512.

22. Bakker AB, Demerouti $E$, de Boer $E$, et al. Job demands and job resources as predictors of absence duration and frequency. $J$ Vocat Behav 2003;62:341-56.

23. Bakker AB, Demerouti E. The Job Demands-resources model: state of the art. Journal of Managerial Psychology 2007;22:309-28.

24. Bakker AB, Demerouti E, Euwema MC. Job resources buffer the impact of job demands on burnout. J Occup Health Psychol 2005;10:170-80.

25. Hobfoll SE, Johnson RJ, Ennis N, et al. Resource loss, resource gain, and emotional outcomes among inner city women. J Pers Soc Psychol 2003;84:632-43.

26. Lazarus RS, Folkman S. Stress, appraisal, and coping. New York: Springer, 1984. 
27. Bandura A. Self-efficacy: toward a unifying theory of behavioral change. Psychol Rev 1977;84:191-215.

28. Xanthopoulou D, Bakker AB, Demerouti E, et al. The role of personal resources in the job demands-resources model. Int J Stress Manag $2007 ; 14: 121-41$

29. Xanthopoulou D, Bakker AB, Demerouti E, et al. Reciprocal relationships between job resources, personal resources, and work engagement. J Vocat Behav 2009;74:235-44.

30. Airila A, Hakanen JJ, Schaufeli WB, et al. Are job and personal resources associated with work ability 10 years later? the mediating role of work engagement. Work Stress 2014;28:87-105.

31. Jackson EM, Dishman RK. Cardiorespiratory fitness and laboratory stress: a meta-regression analysis. Psychophysiology 2006;43:57-72.

32. Hamer M, Steptoe A. Association between physical fitness, parasympathetic control, and proinflammatory responses to mental stress. Psychosom Med 2007;69:660-6.

33. Viswesvaran C, Sanchez JI, Fisher J. The role of Social support in the process of work stress: a Meta-Analysis. J Vocat Behav 1999;54:314-34

34. Engel GL. The need for a new medical model: a challenge for biomedicine. Science 1977;196:129-36.

35. Mayerl H, Stolz E, Waxenegger A, et al. The role of Personal and Job Resources in the relationship between Psychosocial Job Demands, Mental Strain, and Health problems. Front Psychol 2016;7:1214.

36. Bandura A. Self-efficacy mechanism in human agency. Am Psychol 1982;37:122-47.

37. Schwarzer R, Bäßler J, Kwiatek P, et al. The Assessment of optimistic Self-beliefs: comparison of the German, Spanish, and chinese versions of the General Self-efficacy Scale. Appl Psychol 1997;46:69-88.

38. Kopelman P. Health risks associated with overweight and obesity. Obes Rev 2007;8 Suppl 1:13-17.

39. Mohr G, Müller A, Rigotti T, et al. The Assessment of Psychological Strain in Work Contexts. European Journal of Psychological Assessment 2006;22:198-206.

40. Fromm E. The Sane Society. 2nd ed. London: Routledge \& Kegan Paul, 1955.

41. Kanungo RN. The concepts of alienation and involvement revisited. Psychol Bull 1979;86:119-38.

42. Maslach C, Schaufeli WB, Leiter MP. Job burnout. Annu Rev Psychol 2001;52:397-422.

43. Mohr G, Rigotti T, Müller A. Irritation - ein instrument zur Erfassung psychischer Beanspruchung im arbeitskontext. Skalen- und itemparameter aus 15 Studien. Zeitschrift für Arbeits- und Organisationspsychologie A\&O 2005;49:44-8.

44. Freidl W. The impact of Anomia as a factor in a demand resource model of health. Soc Sci Med 1997;44:1357-65.

45. Maslach $C$, Jackson SE. The measurement of experienced burnout. J Organ Behav 1981;2:99-113.

46. Schwarzer R, Jerusalem M. Generalized self-efficacy scale. In: Weinman J, Wright S, Johnston M, eds. Measures in health psychology: a user's portfolio. Causal and control beliefs. Windsor, England: NFER-NELSON, 1995:35-7.

47. Schwarzer R, Jerusalem M. Skalen Zur Erfassung Von Lehrerund Schülermerkmalen: dokumentation der psychometrischen
Verfahren im Rahmen der Wissenschaftlichen Begleitung des Modellversuchs Selbstwirksame Schulen. Berlin: Freie Universität Berlin, 1999.

48. Muthén B. A general structural equation model with dichotomous, ordered categorical, and continuous latent variable indicators. Psychometrika 1984;49:115-32.

49. Jöreskog KG. Structural equation modeling with ordinal variables. Multivariate analysis and its applications. Hayward, CA: Institute of Mathematical Statistics, 1994:297.

50. Lt H, Bentler PM. Cutoff criteria for fit indexes in covariance structure analysis: conventional criteria versus new alternatives. Struct Equ Modeling 1999;6:1-55.

51. Rubin DB. Multiple imputation for nonresponse in surveys. New York: John Wiley \& Sons, 1987.

52. Core Team R. R: a language and environment for Statistical Computing. Vienna, Austria: R Foundation for Statistical Computing, 2017. http://www.R-project.org/

53. Rosseel Y. Lavaan : An $R$ Package for Structural Equation Modeling. $J$ Stat Softw 2012;48:1-36.

54. Sv B, Groothuis-Oudshoorn K. Mice: multivariate imputation by Chained Equations in R. J Stat Softw 2011:45:1-67.

55. Head J, Kivimäki M, Martikainen P, et al. Influence of change in psychosocial work characteristics on sickness absence: the Whitehall II Study. J Epidemiol Community Health 2006;60:55-61.

56. Kuper H, Marmot M. Job strain, job demands, decision latitude, and risk of coronary heart disease within the Whitehall II study. $J$ Epidemiol Community Health 2003;57:147-53.

57. Godin I, Kittel F, Coppieters Y, et al. A prospective study of cumulative job stress in relation to mental health. BMC Public Health 2005;5:67.

58. Stansfeld SA, Fuhrer R, Shipley MJ, et al. Work characteristics predict psychiatric disorder: prospective results from the Whitehall II Study. Occup Environ Med 1999;56:302-7.

59. Lallukka T, Laaksonen M, Martikainen P, et al. Psychosocial working conditions and weight gain among employees. Int $\mathrm{J}$ Obes 2005;29:909-15.

60. Kivimäki M, Head J, Ferrie JE, et al. Work stress, weight gain and weight loss: evidence for bidirectional effects of job strain on body mass index in the Whitehall II study. Int J Obes 2006;30:982-7.

61. Brown JD. Staying fit and staying well: physical fitness as a moderator of life stress. J Pers Soc Psychol 1991;60:555-61.

62. Ensel WM, Lin N. Physical fitness and the stress process. J Commun Psychol 2004;32:81-101.

63. Crews DJ, Landers DM. A meta-analytic review of aerobic fitness and reactivity to psychosocial stressors. Med Sci Sports Exerc 1987;19:S121-S129.

64. McEwen BS. Protective and damaging effects of stress mediators. $N$ Engl J Med 1998;338:171-9.

65. Freidl W, Rásky E, Stronegger WJ. Operationalisation of a demand/ resource model of health: an explorative study. $J$ Epidemiol Community Health 1999;53:187-8.

66. Konttinen H, Silventoinen K, Sarlio-Lähteenkorva S, et al. Emotional eating and physical activity self-efficacy as pathways in the association between depressive symptoms and adiposity indicators. Am J Clin Nutr 2010;92:1031-9. 